\title{
Advances in Understanding Mechanisms of Thrombophilic Disorders
}

\author{
Björn Dahlbäck ${ }^{1}$ \\ ${ }^{1}$ Department of Translational Medicine, University Hospital, Lund \\ University, Malmö, Sweden
}

Hämostaseologie 2020;40:12-21.
Address for correspondence Björn Dahlbäck, MD, PhD, Professor, Department of Translational Medicine, University Hospital, Lund University, Malmö, Sweden (e-mail: bjorn.dahlback@med.lu.se).

\begin{abstract}
Keywords

- APC resistance

- FV Leiden

- TFPI

Venous thromboembolism constitutes a major medical problem afflicting millions of individuals worldwide each year. Its pathogenesis is multifactorial, involving both environmental and genetic risk factors. The most common genetic risk factor known to date is a mutation in the factor $\mathrm{V}$ (FV) gene (R506Q or FV Leiden), which impairs the normal regulation of $\mathrm{FV}$ by activated protein $\mathrm{C}$ (APC). APC is an important regulator of blood coagulation, cleaving and inactivating not only FV/FVa but also activated factor VIII (FVIIIa). In FVa, APC cleaves several sites, Arg506 (R506) being one of them. The R506Q mutation results in the APC resistance phenotype and a lifelong hypercoagulable state. A prothrombin gene mutation is another relatively frequent thrombosis risk factor, whereas deficiencies of the anticoagulant proteins antithrombin, protein $C$, or protein $\mathrm{S}$ are less common. As a result of the high prevalence of $\mathrm{FV}$ and prothrombin mutations in the general population, combinations of genetic defects are relatively common. Such individuals have highly increased risk of thrombosis.
\end{abstract}

\section{Initiation and Propagation of Blood Coagulation}

Circulating platelets adhere to subendothelial structures at sites of vascular damage. A series of reactions is initiated that result in the formation of a platelet plug. Concomitant to these primary hemostatic events, blood coagulation is activated by the exposure of tissue factor (TF), which binds activated factor VII (FVIIa). ${ }^{1,2}$ A cascade of proteolytic reactions-referred to as the extrinsic pathway or the TF pathway - follows that culminates in the formation of thrombin ( - Fig. 1). Thrombin expresses several procoagulant properties, for example, it activates platelets, amplifies the coagulation process by activating factor XI (FXI) and procofactors FV and FVIII, activates factor FXIII (FXIII), and converts fibrinogen into a fibrin network. The FVIIa-TF complex activates both factor IX (FIX) and factor X (FX). ${ }^{3-5}$ Activated FIX (FIXa) activates FX, which in turn activates prothrombin to thrombin. FIXa and FXa are inefficient enzymes requiring negatively charged phospholipid surfaces, protein cofactors,

received

August 30, 2019

accepted after revision

October 21, 2019

and calcium ions for expression of full activity. The cofactors are the activated forms of factor VIII (FVIIIa) and factor V (FVa), respectively. FV and FVIII are high-molecular-weight proteins sharing the modular arrangement A1, A2, B, A3, C1, and $\mathrm{C} 2{ }^{6-8}$ On activation by thrombin or FXa, peptide bonds surrounding the B-modules are cleaved. In circulation, FVIII is bound to von Willebrand factor (VWF) and the thrombinmediated activation of FVIII results in the release of FVIIIa from VWF. ${ }^{9}$

The TF pathway is the physiological activation mechanism associated with traumatic injury. Coagulation can also be activated through the intrinsic pathway after exposure of blood to negatively charged surfaces. ${ }^{1,10-12}$ This system comprises the contact phase proteins (FXII, FXI, prekallikrein, and high-molecular-weight kininogen). The intrinsic pathway does not appear to be physiologically important for injury-related coagulation in vivo, illustrated by the lack of bleeding problems in individuals with deficiency of FXII. ${ }^{13}$ However, the interest in the intrinsic pathway has increased dramatically in the last decade after the discovery that it may

(c) 2020 Georg Thieme Verlag KG Stuttgart . New York
DOI https://doi.org/ 10.1055/s-0040-1701612. ISSN 0720-9355. 


\section{Activation and propagation of coagulation}

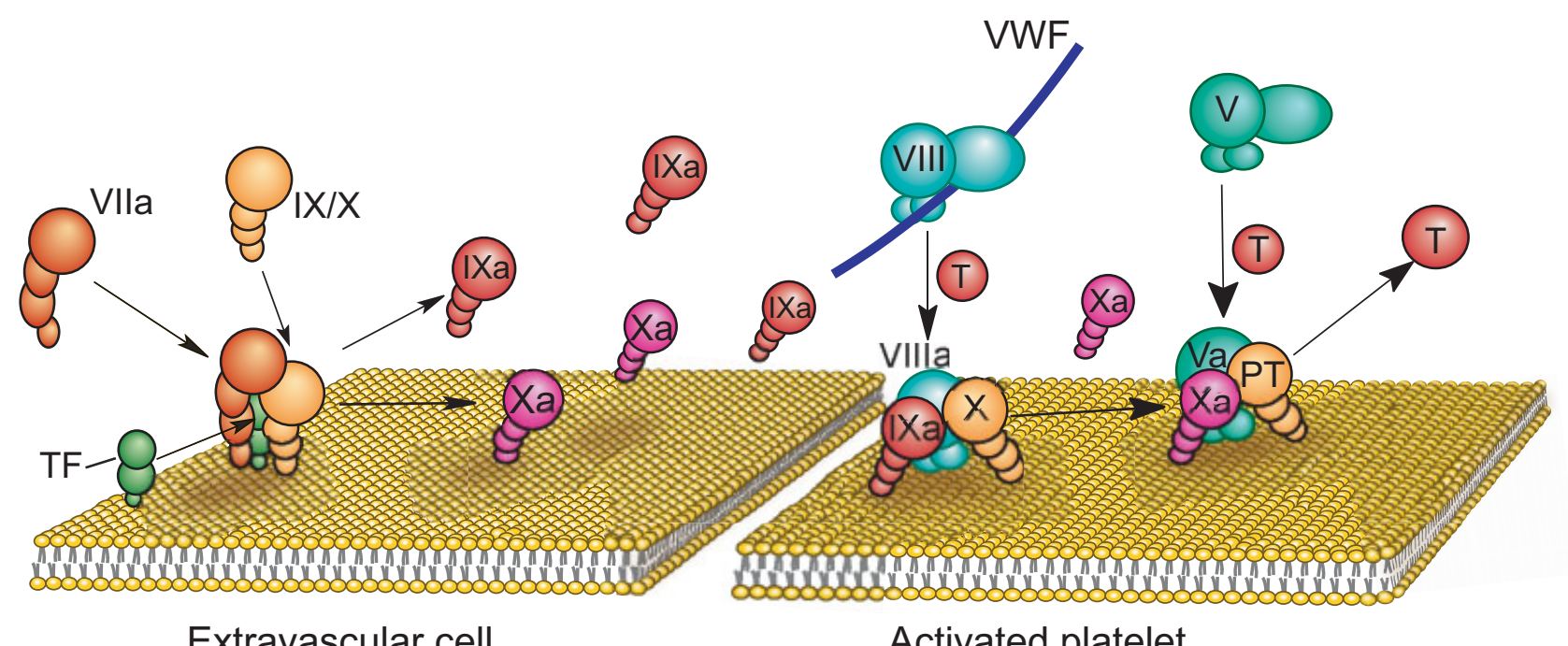

Fig. 1 Initiation and propagation of blood coagulation. During activation of blood coagulation, enzymes and cofactors form complexes that efficiently convert their respective proenzyme substrates to active enzymes. The exposure of tissue factor (TF) to blood initiates the clotting process by binding factor VII/factor VIIa (FVIIa). TF/FVIIa activates factor IX and factor X. The tenase (factor IXa/factor VIIIa) and prothrombinase (factor Xa/factor Va) complexes assemble on the surface of negatively charged phospholipid membranes (mainly provided by platelets). This results in amplification, propagation, and generation of high concentrations of thrombin $(T)$. The initial thrombin that is formed, feedback activates factor VIII (circulating with von Willebrand factor) and factor V.

be important for the formation of arterial thrombosis, and efforts are being made to develop inhibitors to the system for safe anticoagulation. ${ }^{10,14}$ Another discovery that has sparked the interest in the intrinsic pathway is that platelets contain negatively charged polyphosphates that may serve as a natural activator for the intrinsic system. ${ }^{11}$

\section{Regulation of Coagulation}

The coagulation system is strictly regulated at each level of the pathway. Membrane-bound molecules on endothelial cells, circulating inhibitors, and negative feedback mechanisms provide efficient control. Pro- and anticoagulant mechanisms are balanced in favor of anticoagulation under physiological conditions, whereas procoagulant forces prevail at sites of vascular damage. Defects in this ingenious system are associated with increased thrombin generation and a hypercoagulable state that increases the risk of thrombosis.

Antithrombin (AT) is the most important serine protease inhibitor (serpin) regulating coagulation. ${ }^{15}$ It inhibits thrombin, FXIa, FIXa, FXa, and FVIIa. AT is stimulated by heparan sulfate proteoglycans present on the endothelial cell surface. In clinical situations, heparin injections are used to stimulate AT and thus inhibit coagulation.

The TF pathway inhibitor (TFPI) regulates the TF pathway. ${ }^{16,17}$ The full length TFPI (TFPI $\alpha$ ) inhibits the FVIIa-TFFXa complex, thus efficiently turning off the TF pathway. TFPI also directly inhibits FXa, in a phospholipid-bound reaction that is stimulated by protein $\mathrm{S}$ and FV. ${ }^{18}$ Recently, a splice isoform of FV (FV-Short) having a truncated B-domain, which exposes a high-affinity binding site for TFPI $\alpha$, is shown to be a carrier for TFPI $\alpha$ in circulation as well as an efficient synergistic TFPI $\alpha$ cofactor in synergy with protein $S^{8,19-21}$

The procoagulant reactions of thrombin are physiologically adequate at sites of vascular injury. However, intact endothelium converts thrombin into an efficient initiator of a natural anticoagulant pathway, the protein $\mathrm{C}$ system. ${ }^{22-25}$ On endothelium, thrombin binds thrombomodulin, a potent modulator of thrombin activity and a cofactor to thrombin in the activation of protein C ( - Fig. 2 ). In addition, the endothelial protein $C$ receptor stimulates the activation of protein $C$ by the thrombin-thrombomodulin complex. Activated protein $\mathrm{C}$ (APC) inactivates membrane-bound FVa and FVIIIa by limited proteolysis in reactions that are potentiated by a cofactor protein designated protein $\mathrm{S}$ and, in the case of FVIIla degradation, also by the nonactivated form of FV (-Fig. 3). APC cleaves three peptide bonds in FVa at Arg306, Arg506, and Arg679, whereas FVIIIa is cleaved at Arg336 and Arg526. As a consequence of the APC-mediated cleavages, FVa and FVIIIa lose their procoagulant properties. ${ }^{6-8,26,27}$

Protein $\mathrm{C}$ is a vitamin K-dependent plasma protein homologous to FVII, FIX, and FX and shares with them a common modular organization; a vitamin K-dependent $\gamma$ carboxyglutamic acid (Gla)-rich module, two epidermal growth factor (EGF)-like modules, and a serine protease module. ${ }^{23,24,28-30}$ Efficient anticoagulant function of APC depends on the presence of its cofactor protein S. The APCmediated degradation of FVIIIa in the FIXa-FVIIIa complex in addition to protein $S$ requires the presence of $F V$, which in this scenario works as an anticoagulant protein. 7,31,32 The synergistic APC cofactor activity of FV and protein $\mathrm{S}$ is stimulated by APC-mediated cleavage at Arg506. The Arg506 $\rightarrow$ Gln mutation impairs the anticoagulant effect of 


\section{Activation of protein C}

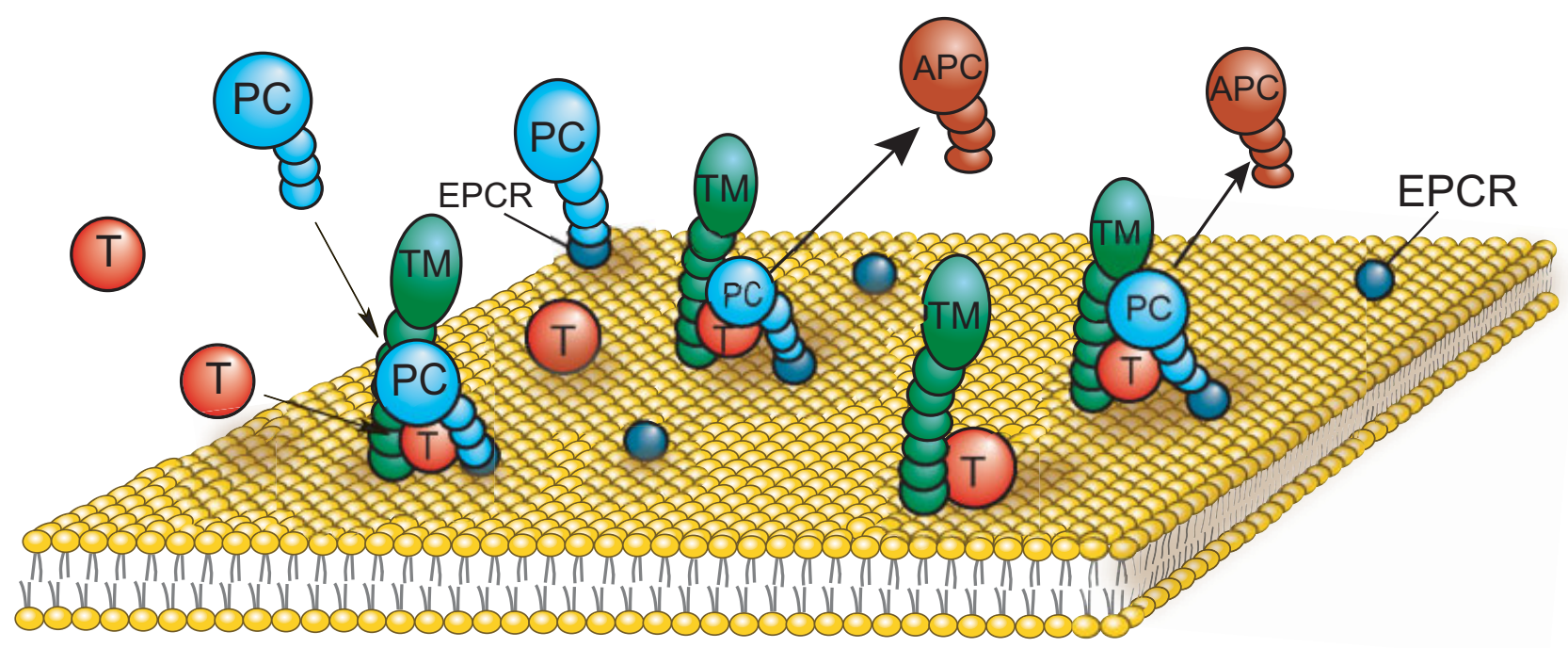

Fig. 2 Activation of protein C (PC) by thrombin-thrombomodulin. On all endothelial cells, thrombomodulin (TM) serves as a cofactor to thrombin $(T)$ in the activation of PC. The endothelial protein $C$ receptor supports the activation by binding the Gla-domain of $P C$ thus presenting PC to the T/TM complex. The activated protein C (APC) floats along with the blood stream to control reactions of coagulation.

FV, which is part of the mechanism of APC resistance (FV Leiden [FVL]; see below). FV loses its APC cofactor activity upon proteolysis by thrombin, but it gains procoagulant properties as a cofactor to FXa. Thus, FV is similar to thrombin in being able to express both procoagulant and anticoagulant effects. ${ }^{8,31}$
Protein S is a multimodular vitamin K-dependent plasma protein, but not a serine protease. It contains a Gla module, a thrombin-sensitive module, four EGF-like modules, and a large module homologous to sex hormone-binding globulin. ${ }^{33}$ In plasma, 60 to $70 \%$ of protein $S$ circulates bound to C4b-binding protein (C4BP), a regulator of the complement

\section{Inhibition of coagulation by APC}

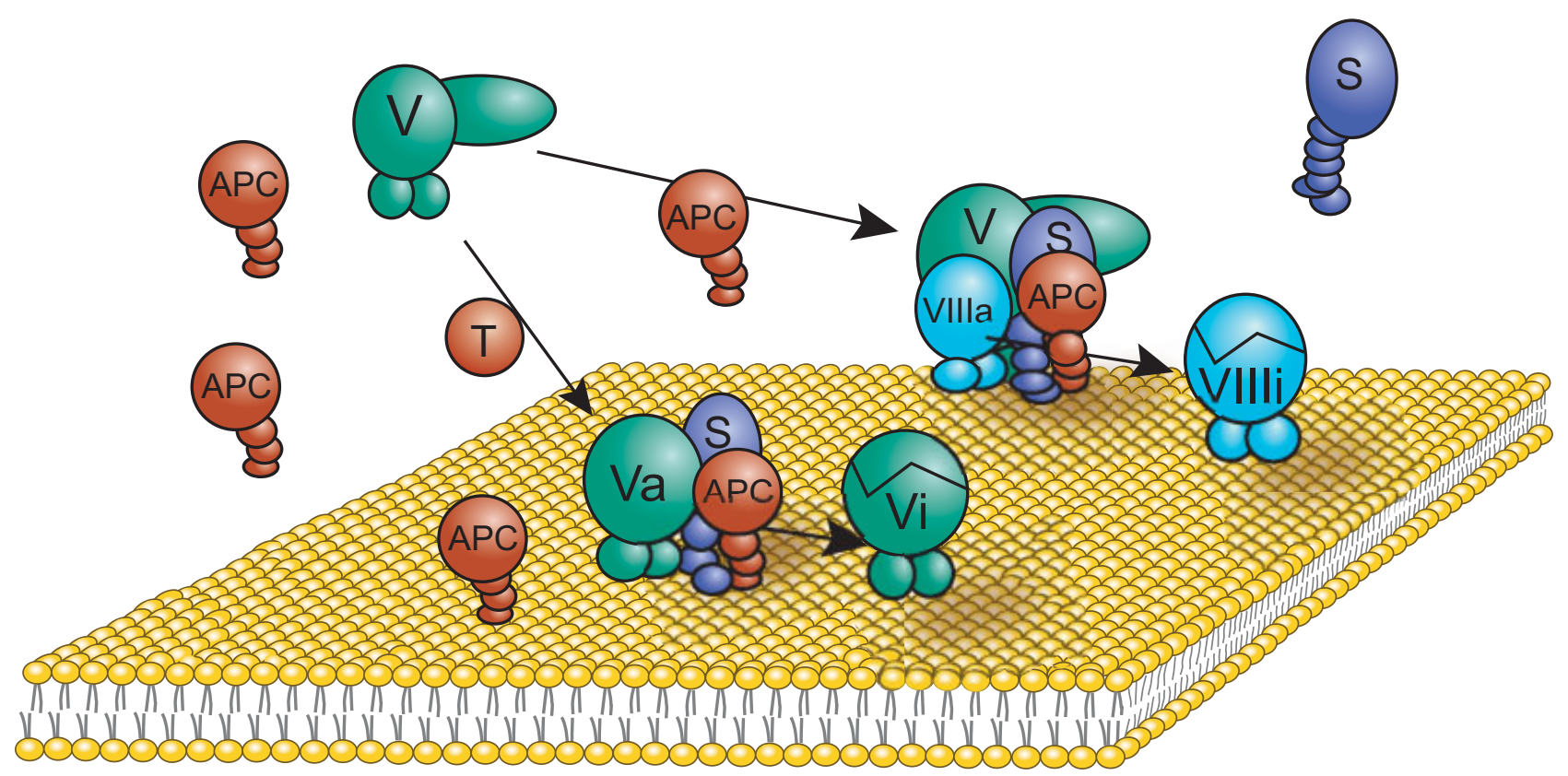

Fig. 3 Degradation of factor Va (FVa) and factor VIIla (FVIIla) by activated protein C (APC). FVa and FVIIla are cleaved and inhibited by APC in reactions involving APC cofactors protein S and factor V (FV). Protein S and APC are sufficient to inhibit FVa, whereas FVIIla regulation additionally involves $\mathrm{FV}$, which in this reaction serves as cofactor to APC. 
system demonstrating that protein has functions outside the protein C system. ${ }^{27}$ The Gla module of protein S is instrumental in binding to membranes containing phosphatidylserine, for example, exposed on apoptotic cells, which is important for their elimination by phagocytosis.

In the degradation of FVa by APC, the Arg506 cleavage is faster than that at Arg306 but only yields partial loss of FVa activity. In contrast, cleavage at Arg306 results in efficient loss of FVa activity. Protein $S$ serves as cofactor for the cleavage at Arg306 but has minor effects on the Arg506 cleavage. ${ }^{23,24}$ The synergistic TFPI $\alpha$-cofactor activity between protein $\mathrm{S}$ and FV/FV-Short in the inhibition of FXa is an anticoagulant activity of protein $S$ that is potentially physiologically important. $8,19,20,34$ The importance of the anticoagulant protein S functions in vivo is clearly demonstrated by the association between protein S deficiency and venous thromboembolism (VTE) in humans and by the lethal thrombotic phenotype associated with protein $\mathrm{S}$ knockout in mice. 27,35

\section{Genetics of Thrombophilia}

In Western societies, the annual incidence of VTE is approximately 1 to 2 per $1,000 .^{26,36-39}$ Thrombosis often occurs in conjunction with pregnancy, the use of oral contraceptives, surgery, fractures, and immobilization. Genetic factors are frequently involved and patients often report family histories of VTE. ${ }^{37}$ The most common genetic risk factors for VTE are point mutations in the FV gene (F5) and in the prothrombin gene (F2), whereas deficiencies of anticoagulant protein C, protein S, or AT are less common. ${ }^{26,28,36,38,40}$ These inherited causes of thrombophilia result in a lifelong increased risk of thrombosis. However, the individual risk profile is difficult to predict as many other genetic and environmental factors affect the risk.

\section{Factor V Gene Mutations Causing APC Resistance}

In 1993, we described the APC resistance phenotype as a highly prevalent cause of inherited thrombophilia and in 1994 we reported its association with FV. ${ }^{41,42}$ Shortly thereafter, many laboratories confirmed its high prevalence among thrombosis patients (20-60\%). ${ }^{43-45}$ The characteristic feature of APC resistance is that the addition of APC to plasma in a clotting test does not give a normal prolongation of the coagulation time. ${ }^{41}$ The $F 5$ gene (GeneID 2153, OMIM ID $227400,188055,612309$ ) was soon shown to be the involved gene and around 95\% of cases carries a single-point mutation in F5; a G $\rightarrow$ A substitution predicts replacement of R506 with a $\mathrm{Q}(\mathrm{Gln}) .^{46-50}$ The mutant F5 is referred to as FVL, or FVR506Q, or FV:Q506 ( $R$ and Q are one-letter codes for Arg and Gln, respectively; - Fig. 4). Other rare F5 mutations causing APC resistance include FVNara (W1920R) and FVBonn (A512V). ${ }^{51,52}$ Other cases with APC resistance where F5 mutations have been found but not proven to be the cause include FV E666D in a Chinese family, and three mutations in venous thrombosis patients with Chilean Amerindian ethnic background-FV M443L, FV E461Q, and FV G493E. Two rare mutations affecting the Arg306 cleavage site, FV Cambridge (R306T) and FV Hong Kong (R306G), do not result in APC resistance and are not risk factors for VTE.

The FVL allele is found in individuals with Caucasian genetic background. ${ }^{26,36,38}$ In southern Sweden, Germany, Greece, Arab countries, and Israel, high prevalence (up to $15 \%$ ) is found. In the United States, the United Kingdom, and the Netherlands, around 3 to $5 \%$ carry the mutant allele. Lower prevalence (around 2\%) is found in Hispanics. Its high prevalence suggests a survival advantage, and an associated reduced risk of bleeding after delivery has been shown. The slightly increased risk of VTE associated with the FVL has

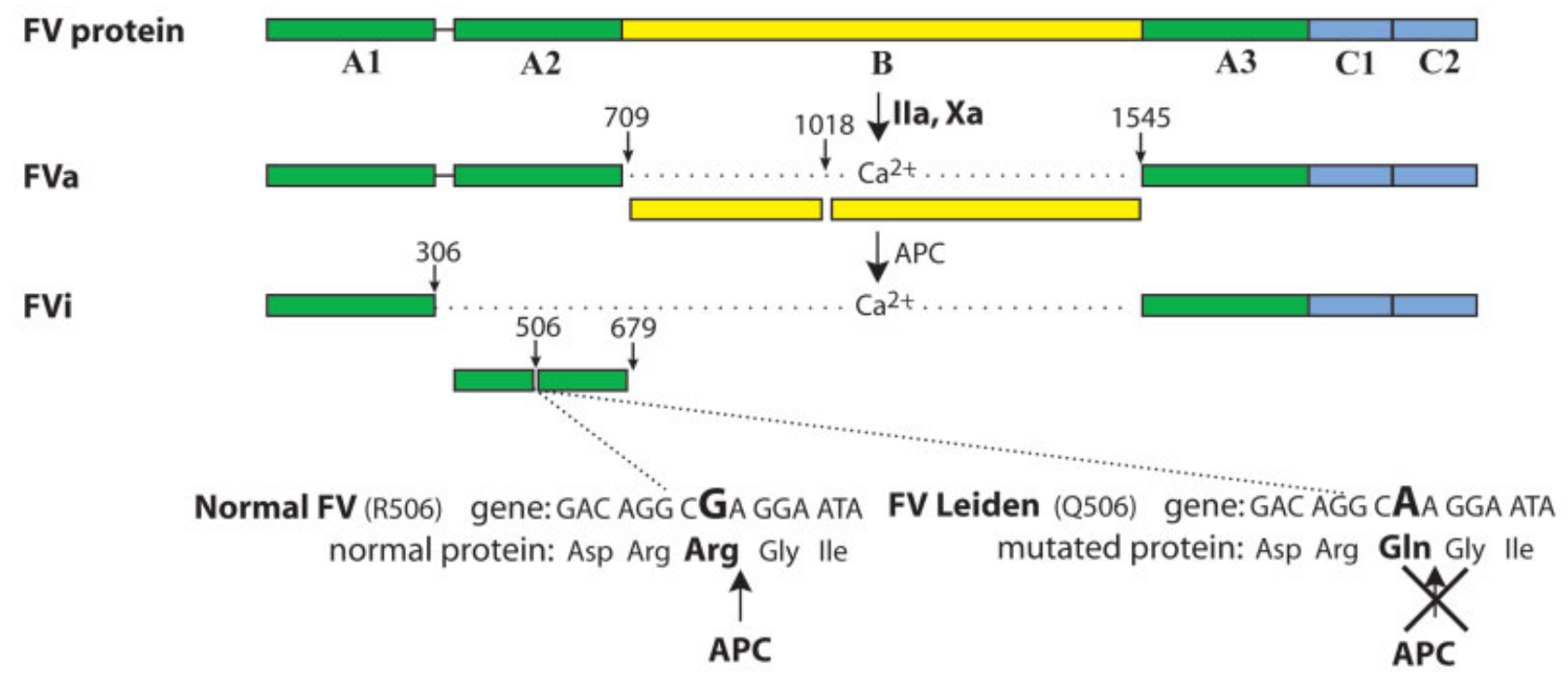

Fig. 4 Activation and degradation of normal factor V (FV) and FV Leiden (FVL). FV is a high-molecular-weight single-chain protein. Thrombin (or FXa) cleaves several peptide bonds, thus liberating the B domain and generating factor Va (FVa). During inhibition of FVa, three peptide bonds are cleaved (Arg306, Arg506, and Arg679). In activated protein C resistance, due to the FVL mutation, the Arg506 cleavage site is lost. 
likely not been a negative survival factor in the history of humankind as VTE develops relatively late in life and does not negatively influence fertility. In addition, our ancestors were not affected by modern circumstantial risk factors for VTE, such as a sedentary lifestyle, surgery, and the use of oral contraceptives.

The FVL allele is the result of a founder effect, the mutation event estimated to have taken place around 20,000 years ago, after the "Out of Africa Exodus" and the separation of Asians from Europeans. ${ }^{53}$ This explains why the FVL is common among European populations but rare in China, Japan, and in the original populations of Africa, Australia, or Americas.

The general consensus is that the FVL is the most common genetic risk factor for VTE in Western societies but is not a risk factor for arterial thrombosis. ${ }^{26,28,36,38,39}$ The odds ratio for VTE has been estimated to be two- to threefold in heterozygous cases, whereas homozygous individuals are at higher risk. FVL is associated with a hypercoagulable state caused by two molecular mechanisms, one being an impaired inhibition of FVa by APC, the other being that FVL functions as a poor APC cofactor in the degradation of FVIIIa. ${ }^{26,31,32}$ In FVa degradation, the Arg506 cleavage is approximately 10 -fold faster than the cleavage at Arg306 and mutant FVa is therefore inhibited at an approximately 10 -fold lower rate than normal FVa. However, degradation of FVa in the prothrombinase (PTase) complex is different from that of free FVa because in the PTase the Arg506 site is protected from degradation by APC by both FXa and prothrombin. Moreover, protein S functions as an APC cofactor primarily for the Arg306 cleavage. Therefore, APC-mediated inhibition of FVa in the PTase follows a different pathway compared with that of free FVa. As a consequence, when mutant and normal FVa are part of assembled PTase com- plexes, their rates of degradation by APC and protein S are relatively similar.

\section{Prothrombin Gene Mutations}

The second most common genetic risk factor for VTE is a point mutation in the prothrombin gene, F2 (GeneID 2147, OMIM ID 176930.0009), G20210A located in the 3' untranslated regions (-Fig. 5), which is associated with approximately twofold increased risk of VTE. ${ }^{26,36,38,40}$ The mutation is associated with increased plasma levels of prothrombin due to increased efficiency of the $F 2$ gene mRNA. Its prevalence is 0 to $5 \%$ in the general population. Similar to the FVL, the F2 20210A variant originated from a single mutational event and the allele is only found in Caucasian populations.

Another F2 gene gain-of-function mutation was found in a Japanese family with VTE. The mutation results in a substitution of Arg for Leu at position 596 and is located in the last exon of the F2 gene (OMIM ID 176930.0015). Arg596 is located in a region containing AT-binding sites and it is anticipated that the mutation causes AT resistance. Two other mutations affecting the same amino acid residue (Arg596Gln and Arg596Trp) have been linked to VTE and AT resistance.

\section{Antithrombin Deficiency}

AT deficiency is caused by mutations in the AT gene SERPINC1 (GeneID 462, OMIM ID 107300, 613118) located at chromosome 1q23-q25. Heterozygous AT deficiency is found in 1 to $2 \%$ of VTE patients and in 0.02 to $0.05 \%$ of the general population suggesting a 10 -fold increased risk of VTE. ${ }^{15,54,55}$ Type I deficiency is characterized by low AT plasma concentration, whereas type II denotes functional

\section{Prothrombin gene}

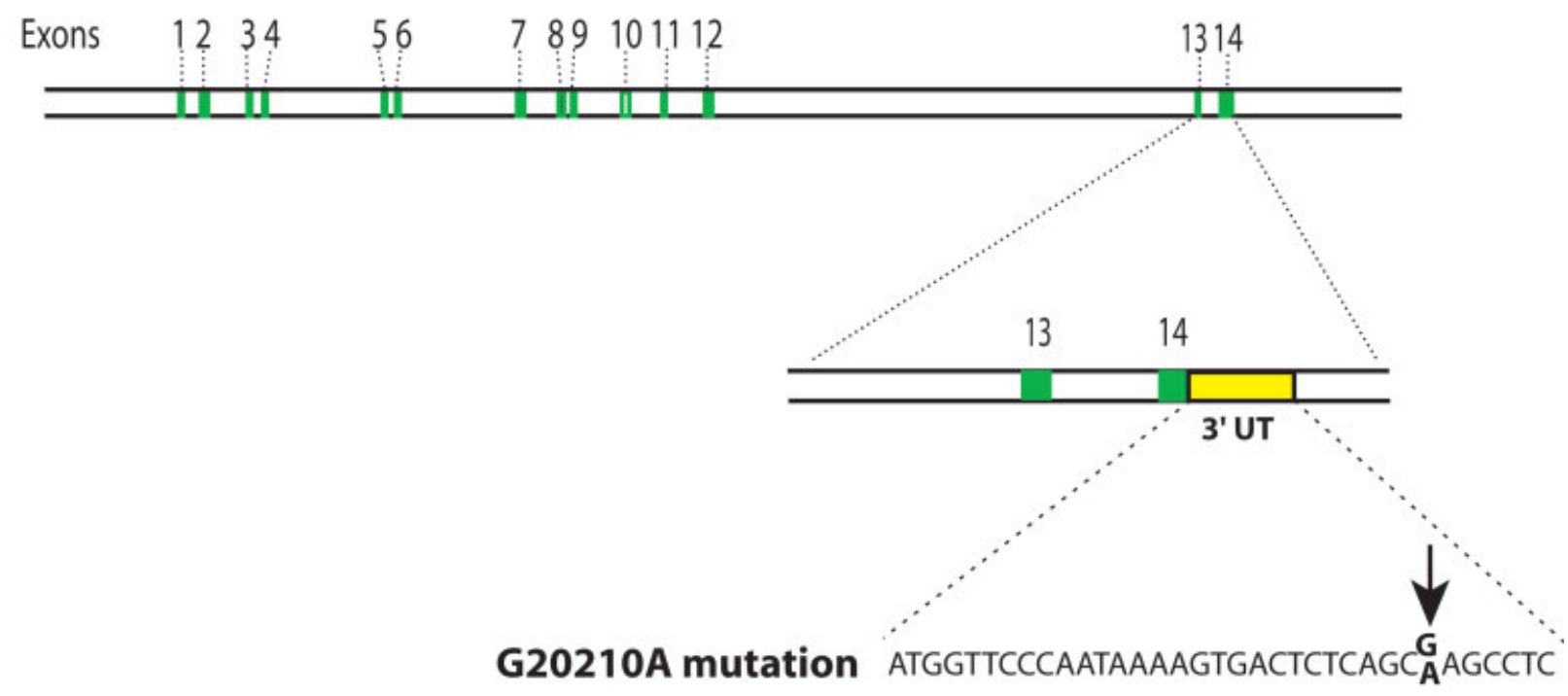

Fig. 5 G20210A mutation in the prothrombin gene. The G to A single-point mutation affects the $3^{\prime}$ untranslated region of the prothrombin gene (F2). The mutation is not affecting the coding sequence but increases the prothrombin plasma concentration and thus the risk of thrombosis. 
defects. Type II can be further divided into three subtypes: reactive site (RS) mutants, heparin-binding site (HBS) mutants, or mutants giving pleiotropic effects (PE). According to the Human Gene Mutation Database (www.hgmd.cf. ac.uk/ac), there are several hundred distinct SERPINC1 gene mutations reported. Type II RS variants are functionally defective in protease inactivation often due to mutations in the vicinity of the RS. The type II HBS deficiency carries mutations in the HBS, and type II PE variants are caused by a limited number of mutations between amino acids 402 and 429.

\section{Protein C Deficiency}

Protein C deficiency is caused by mutations in the protein C gene PROC (GeneID 5624, OMIM ID 176860, 612304) on chromosome $2 \mathrm{q} 13-\mathrm{q} 21$. Type I is characterized by decreased protein $\mathrm{C}$ antigen and functional activity. Type II is caused by functional defects and the plasma protein $C$ concentration may be normal. Heterozygous deficiency is found in a few percentage of VTE cases and in approximately $0.3 \%$ in the general population, and the relative risk of VTE is similar to that of FVL. ${ }^{26,28,29,36,38}$ Homozygous or compound heterozygous protein $\mathrm{C}$ deficiency is a rare condition ( 1 in 200,000-400,000) which causes severe and fatal microvascular thrombosis in the neonatal period with purpura fulminans, necrotic skin lesions, eye and brain damage, and disseminated intravascular coagulation. Several cases have been successfully treated with fresh frozen plasma or with protein C concentrates followed by lifelong anticoagulant treatment. The Human Gene Mutation Database (www. hgmd.cf.ac.uk/ac) lists several hundred distinct mutations associated with protein $C$ deficiency. Most genetic defects are missense mutations, which lead to single amino acid substitutions, or nonsense mutations, located within the coding region of the gene. Type I mutations are scattered over the entire polypeptide chain. Type II mutations are less common but have been found in almost all the domains of protein $\mathrm{C}$.

\section{Protein S Deficiency}

Protein S deficiency is caused by mutations in the protein S gene PROS1 (GeneID 5627, OMIM ID 176880, 612336, 614514) located close to the centromere at chromosome 3p11.1-q11.2. A pseudogene (PROSP, GeneID 5628) is located in close vicinity and shares more than $95 \%$ similarity with PROS1, which complicates genetic investigations of PROS1. Phenotyping for protein $\mathrm{S}$ deficiency is complicated by the presence in plasma of both free and C4BP-bound protein $\mathrm{S}$ $(27,33,35)$. We have demonstrated that the concentration of free protein $\mathrm{S}$ discriminates better between those with and without protein $S$ deficiency than the level of total protein $S$. The molecular explanation for this is that in individuals with normal PROS1 alleles the plasma concentration of protein $\mathrm{S}$ is slightly higher than that of $\mathrm{C} 4 \mathrm{BP} \beta^{+}$, which is the protein Sbinding isoform of $\mathrm{C} 4 \mathrm{BP}^{56}{ }^{5}$ The binding affinity of protein $\mathrm{S}$ to $\mathrm{C} 4 \mathrm{BP} \beta^{+}$is very high and therefore all $\mathrm{C} 4 \mathrm{BP} \beta^{+}$molecules are occupied with protein $S$. The molar surplus of protein $S$ constitutes the free pool of protein $S$ in plasma. In contrast, in protein S-deficient individuals the concentrations of protein $S$ and $C 4 \mathrm{BP}^{+}$are equimolar and most of protein $\mathrm{S}$ is bound to $\mathrm{C} 4 \mathrm{BP} \beta^{+}$, and as a consequence the free protein $S$ is low. Type I protein $\mathrm{S}$ deficiency is characterized by low levels of both free and total protein S. Protein S deficiency demonstrating low free protein $S$ and normal total protein $S$ has been believed to constitute a separate genetic type (type III). However, coexistence of the two types in many protein Sdeficient families demonstrates that they represent different phenotypic variants of the same genetic disease. ${ }^{56}$ Type II deficiency denotes cases with normal free and total protein $S$ but with low protein $S$ function. To date, very few type II deficiencies have been found, presumably related to poor diagnostic performance of available functional protein $S$ assays. We have recently described a novel functional assay measuring the TFPI $\alpha$ cofactor activity of protein $S$ that is expressed in synergy with FV-Short. ${ }^{20}$ Hopefully, this assay will help identify more patients with type II deficiency.

Heterozygous protein $S$ deficiency is present in a few percentage of VTE patients, whereas the prevalence of protein $\mathrm{S}$ deficiency in the general population of Western societies has been estimated to be 0.03 to $0.13 \%$, but higher figures have been reported from Japan and Thailand. Family studies suggest that heterozygous carriers have at least fivefold increased risk of VTE compared with their healthy relatives, which is similar to the rates in thrombophilic families with protein C deficiency and FVL. Homozygous protein $\mathrm{S}$ deficiency is extremely rare but appears to give a similar picture to homozygous protein C deficiency, with purpura fulminans in the neonatal period. Protein $\mathrm{S}$ knockout mice are embryonic lethal due to uncontrolled coagulation. ${ }^{57,58}$

In the Human Gene Mutation Database (www.hgmd.cf. ac.uk/ac), there are several hundred different PROS1 mutations that may be associated with a protein $\mathrm{S}$ deficiency phenotype. Most of the gene defects are missense or nonsense mutations, and mutations affecting splicing or small insertion/deletion defects are less common. In some families with phenotypically established protein S deficiency, PROS1 gene mutations are not found although linkage between the PROS1 locus and protein S deficiency has been established. One reason may be that common genetic screening techniques miss large deletions.

\section{Large-Scale Genomic Screening Studies}

The heritability of VTE is very high and patients often report positive family history of VTE. A large study of singlenucleotide polymorphisms (SNPs) of a UK Biobank cohort estimated the heritability of VTE to be $\approx 30 \%$, whereas twin studies find even higher numbers $(\approx 50 \%) .{ }^{59,60}$ As the known genetic variants only explain a small fraction of the VTE heritability, additional genetic variants remain to be discovered. Genome-Wide Association Studies (GWAS) have associated several genetic variants to VTE, most of them already known to be involved in hemostasis, such as $A B O, F 2, F 5, F 11$, FGG, and PROCR. ${ }^{61} \mathrm{ABO}$ encodes the blood groups; it has been 
known for many years that individuals with non-0 blood groups have higher risk of VTE. These individuals have high FVIII and VWF concentrations, which may be the mechanism for the increased risk of VTE. FGG mutations causing functional defects in fibrinogen is a rare VTE risk factor. The mechanism for the PROCR association with VTE may be mediated via the influence of the protein $C$ receptor on protein $\mathrm{C}$ activation. Nonhemostatic genes identified were TSPAN15 and SLC44A2 but the mechanisms of their influence on VTE remain to be elucidated. ${ }^{62}$ Next generation sequencing (NGS) have been used to identify rare and low-frequency variants. However, a metanalysis of large-scale exome array analyses of VTE failed to identify novel VTE genes. ${ }^{63}$

\section{Severe Thrombophilia Is a Multigenic Disease}

VTE is a typical multifactorial disease involving one or more environmental and/or genetic risk factors. In Western societies, many individuals have more than one genetic risk factor because of the high prevalence of FVL and F220210A alleles. In contrast, in countries where these alleles are rare, fewer individuals carry more than one genetic defect. This probably explains the VTE incidence difference between Western and Asian countries. The frequency of individuals carrying two or more genetic defects can be calculated on the basis of the prevalence of the individual genetic defects in the general population. Those that carry more than one genetic defect have considerably increased risk of thrombosis. The thrombotic tendency in individuals with one or more inherited genetic defects is highly variable and some individuals never develop thrombosis, whereas others develop recurrent severe thrombotic events at an early age. This depends on the particular genotype, the coexistence of other genetic defects, and the presence of environmental risk factors such as oral contraceptives, trauma, surgery, and pregnancy.

\section{Conflict of Interest}

None.

\section{References}

1 Smith SA, Travers RJ, Morrissey JH. How it all starts: initiation of the clotting cascade. Crit Rev Biochem Mol Biol 2015;50(04): 326-336

2 Grover SP, Mackman N. Tissue factor: an essential mediator of hemostasis and trigger of thrombosis. Arterioscler Thromb Vasc Biol 2018;38(04):709-725

3 Dahlbäck B. Blood coagulation. Lancet 2000;355(9215): 1627-1632

4 Schenone M, Furie BC, Furie B. The blood coagulation cascade. Curr Opin Hematol 2004;11(04):272-277

5 Dahlbäck B. Blood coagulation and its regulation by anticoagulant pathways: genetic pathogenesis of bleeding and thrombotic diseases. J Intern Med 2005;257(03):209-223

6 Camire RM, Bos MH. The molecular basis of factor V and VIII procofactor activation. J Thromb Haemost 2009;7(12): 1951-1961

7 Dahlbäck B. Pro- and anticoagulant properties of factor V in pathogenesis of thrombosis and bleeding disorders. Int J Lab Hematol 2016;38(Suppl 1):4-11
8 Dahlbäck B. Novel insights into the regulation of coagulation by factor $\mathrm{V}$ isoforms, tissue factor pathway inhibitor $\alpha$, and protein $\mathrm{S}$. J Thromb Haemost 2017;15(07):1241-1250

9 Sadler JE. von Willebrand factor assembly and secretion. J Thromb Haemost 2009;7(Suppl 1):24-27

10 Nickel KF, Long AT, Fuchs TA, Butler LM, Renné T. Factor XII as a therapeutic target in thromboembolic and inflammatory diseases. Arterioscler Thromb Vasc Biol 2017;37(01):13-20

11 Morrissey JH, Smith SA. Polyphosphate as modulator of hemostasis, thrombosis, and inflammation. J Thromb Haemost 2015;13 (Suppl 1):S92-S97

12 Mohammed BM, Matafonov A, Ivanov I, et al. An update on factor XI structure and function. Thromb Res 2018;161:94-105

13 Maas C, Renné T. Coagulation factor XII in thrombosis and inflammation. Blood 2018;131(17):1903-1909

14 Tillman B, Gailani D. Inhibition of factors XI and XII for prevention of thrombosis induced by artificial surfaces. Semin Thromb Hemost 2018;44(01):60-69

15 Huntington JA. Thrombin inhibition by the serpins. J Thromb Haemost 2013;11(Suppl 1):254-264

16 Mast AE. Tissue factor pathway inhibitor: multiple anticoagulant activities for a single protein. Arterioscler Thromb Vasc Biol 2016; 36(01):9-14

17 Broze GJ Jr, Girard TJ. Tissue factor pathway inhibitor: structurefunction. Front Biosci 2012;17:262-280

18 Santamaria S, Reglińska-Matveyev N, Gierula M, et al. Factor V has an anticoagulant cofactor activity that targets the early phase of coagulation. J Biol Chem 2017;292(22):9335-9344

19 Dahlbäck B, Guo LJ, Livaja-Koshiar R, Tran S. Factor V-short and protein $S$ as synergistic tissue factor pathway inhibitor (TFPI $\alpha$ ) cofactors. Res Pract Thromb Haemost 2017;2(01):114-124

20 Dahlbäck B, Guo LJ, Zöller B, Tran S. New functional test for the TFPI $\alpha$ cofactor activity of protein S working in synergy with FVshort. J Thromb Haemost 2019;17(04):585-595

21 Vincent LM, Tran S, Livaja R, Bensend TA, Milewicz DM, Dahlbäck B. Coagulation factor V(A2440G) causes east Texas bleeding disorder via TFPI $\alpha$. J Clin Invest 2013;123(09):3777-3787

22 Conway EM. Thrombomodulin and its role in inflammation. Semin Immunopathol 2012;34(01):107-125

23 Dahlbäck B, Villoutreix BO. The anticoagulant protein C pathway. FEBS Lett 2005;579(15):3310-3316

24 Dahlbäck B, Villoutreix BO. Regulation of blood coagulation by the protein $C$ anticoagulant pathway: novel insights into structurefunction relationships and molecular recognition. Arterioscler Thromb Vasc Biol 2005;25(07):1311-1320

25 Esmon CT. Inflammation and the activated protein C anticoagulant pathway. Semin Thromb Hemost 2006;32(Suppl 1):49-60

26 Dahlbäck B. Advances in understanding pathogenic mechanisms of thrombophilic disorders. Blood 2008;112(01):19-27

27 Dahlbäck B. Vitamin K-dependent protein S: beyond the protein C pathway. Semin Thromb Hemost 2018;44(02):176-184

28 Esmon CT. Basic mechanisms and pathogenesis of venous thrombosis. Blood Rev 2009;23(05):225-229

29 Griffin JH, Zlokovic BV, Mosnier LO. Protein C anticoagulant and cytoprotective pathways. Int J Hematol 2012;95(04):333-345

30 Hansson K, Stenflo J. Post-translational modifications in proteins involved in blood coagulation. J Thromb Haemost 2005;3(12): 2633-2648

31 Nicolaes GA, Dahlbäck B. Factor V and thrombotic disease: description of a janus-faced protein. Arterioscler Thromb Vasc Biol 2002;22(04):530-538

32 Segers K, Dahlbäck B, Nicolaes GA. Coagulation factor V and thrombophilia: background and mechanisms. Thromb Haemost 2007;98(03):530-542

33 Dahlbäck B. The tale of protein S and C4b-binding protein, a story of affection. Thromb Haemost 2007;98(01):90-96

34 Hackeng TM, Rosing J. Protein S as cofactor for TFPI. Arterioscler Thromb Vasc Biol 2009;29(12):2015-2020 
35 García de Frutos P, Fuentes-Prior P, Hurtado B, Sala N. Molecular basis of protein $S$ deficiency. Thromb Haemost 2007;98(03): 543-556

36 Wolberg AS, Rosendaal FR, Weitz JI, et al. Venous thrombosis. Nat Rev Dis Primers 2015;1:15006

37 Zöller B, Li X, Ohlsson H, Ji J, Sundquist J, Sundquist K. Family history of venous thromboembolism as a risk factor and genetic research tool. Thromb Haemost 2015;114(05):890-900

38 Martinelli I, De Stefano V, Mannucci PM. Inherited risk factors for venous thromboembolism. Nat Rev Cardiol 2014;11(03): 140-156

39 Raskob GE, Angchaisuksiri P, Blanco AN, et al; ISTH Steering Committee for World Thrombosis Day. Thrombosis: a major contributor to global disease burden. Arterioscler Thromb Vasc Biol 2014;34(11):2363-2371

40 Zöller B, García de Frutos P, Hillarp A, Dahlbäck B. Thrombophilia as a multigenic disease. Haematologica 1999;84(01):59-70

41 Dahlbäck B, Carlsson M, Svensson PJ. Familial thrombophilia due to a previously unrecognized mechanism characterized by poor anticoagulant response to activated protein C: prediction of a cofactor to activated protein C. Proc Natl Acad Sci USA 1993;90 (03):1004-1008

42 Dahlbäck B, Hildebrand B. Inherited resistance to activated protein $\mathrm{C}$ is corrected by anticoagulant cofactor activity found to be a property of factor V. Proc Natl Acad Sci USA 1994;91(04): 1396-1400

43 Griffin JH, Evatt B, Wideman C, Fernández JA. Anticoagulant protein $C$ pathway defective in majority of thrombophilic patients. Blood 1993;82(07):1989-1993

44 Koster T, Rosendaal FR, de Ronde H, Briët E, Vandenbroucke JP, Bertina RM. Venous thrombosis due to poor anticoagulant response to activated protein C: Leiden Thrombophilia Study. Lancet 1993;342(8886-8887):1503-1506

45 Svensson PJ, Dahlbäck B. Resistance to activated protein C as a basis for venous thrombosis. N Engl J Med 1994;330(08):517-522

46 Bertina RM, Koeleman BP, Koster T, et al. Mutation in blood coagulation factor $\mathrm{V}$ associated with resistance to activated protein C. Nature 1994;369(6475):64-67

47 Greengard JS, Sun X, Xu X, Fernandez JA, Griffin JH, Evatt B. Activated protein $C$ resistance caused by Arg506Gln mutation in factor Va. Lancet 1994;343(8909):1361-1362

48 Voorberg J, Roelse J, Koopman R, et al. Association of idiopathic venous thromboembolism with single point-mutation at Arg506 of factor V. Lancet 1994;343(8912):1535-1536

49 Zöller B, Dahlbäck B. Linkage between inherited resistance to activated protein $C$ and factor $V$ gene mutation in venous thrombosis. Lancet 1994;343(8912):1536-1538
50 Zöller B, Svensson PJ, He X, Dahlbäck B. Identification of the same factor $\mathrm{V}$ gene mutation in 47 out of 50 thrombosis-prone families with inherited resistance to activated protein C. J Clin Invest 1994; 94(06):2521-2524

51 Nogami K, Shinozawa K, Ogiwara K, et al. Novel FV mutation (W1920R, FVNara) associated with serious deep vein thrombosis and more potent APC resistance relative to FVLeiden. Blood 2014; 123(15):2420-2428

52 Pezeshkpoor B, Castoldi E, Mahler A, et al. Identification and functional characterization of a novel F5 mutation (Ala512Val, FVB onn ) associated with activated protein C resistance. J Thromb Haemost 2016;14(07):1353-1363

53 Zivelin A, Griffin JH, Xu X, et al. A single genetic origin for a common Caucasian risk factor for venous thrombosis. Blood 1997;89(02):397-402

54 Huntington JA. Serpin structure, function and dysfunction. J Thromb Haemost 2011;9(Suppl 1):26-34

55 Huntington JA. Natural inhibitors of thrombin. Thromb Haemost 2014;111(04):583-589

56 Zöller B, García de Frutos P, Dahlbäck B. Evaluation of the relationship between protein $S$ and $C 4 b$-binding protein isoforms in hereditary protein S deficiency demonstrating type I and type III deficiencies to be phenotypic variants of the same genetic disease. Blood 1995;85(12):3524-3531

57 Saller F, Brisset AC, Tchaikovski SN, et al. Generation and phenotypic analysis of protein S-deficient mice. Blood 2009;114(11): 2307-2314

58 Burstyn-Cohen T, Heeb MJ, Lemke G. Lack of protein S in mice causes embryonic lethal coagulopathy and vascular dysgenesis. J Clin Invest 2009;119(10):2942-2953

59 Klarin D, Emdin CA, Natarajan P, Conrad MF, Kathiresan S; INVENT Consortium. Genetic analysis of venous thromboembolism in UK Biobank identifies the ZFPM2 locus and implicates obesity as a causal risk factor. Circ Cardiovasc Genet 2017;10(02):e001643

60 Heit JA, Phelps MA, Ward SA, Slusser JP, Petterson TM, De Andrade M. Familial segregation of venous thromboembolism. J Thromb Haemost 2004;2(05):731-736

61 Crous-Bou M, Harrington LB, Kabrhel C. Environmental and genetic risk factors associated with venous thromboembolism. Semin Thromb Hemost 2016;42(08):808-820

62 Germain M, Chasman DI, de Haan H, et al; Cardiogenics Consortium. Meta-analysis of 65,734 individuals identifies TSPAN15 and SLC44A2 as two susceptibility loci for venous thromboembolism. Am J Hum Genet 2015;96(04):532-542

63 Lindström S, Brody JA, Turman C, et al; INVENT Consortium. A large-scale exome array analysis of venous thromboembolism. Genet Epidemiol 2019;43(04):449-457 